Research Article

\title{
Influence of Rock Strength on the Propagation of Slotted Cartridge Blasting-Induced Directional Cracks
}

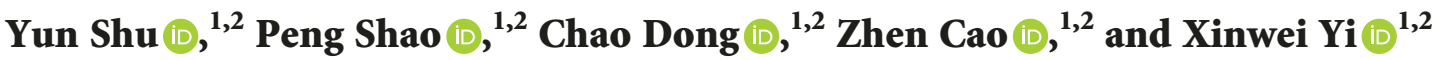 \\ ${ }^{1}$ School of Mechanics and Civil Engineering, China University of Mining and Technology, Xuzhou 221116, China \\ ${ }^{2}$ State Key Laboratory for Geomechanics and Deep Underground Engineering, China University of Mining and Technology, \\ Xuzhou 221116, China \\ Correspondence should be addressed to Peng Shao; spsyc@163.com
}

Received 7 April 2019; Accepted 24 August 2019; Published 26 September 2019

Academic Editor: Rafael J. Bergillos

Copyright (c) 2019 Yun Shu et al. This is an open access article distributed under the Creative Commons Attribution License, which permits unrestricted use, distribution, and reproduction in any medium, provided the original work is properly cited.

\begin{abstract}
Based on theories of explosive mechanics and rock fracture mechanics, the influence mechanism of rock strength on the propagation length of the primary crack in the directional fracture blasting with slotted cartridge has been investigated deeply to propose the relation equation between the rock strength and the propagation length of the primary crack. Theoretically, the maximum length $a_{\mathrm{m}}$ of the primary crack increases with the enhancing rock strength parameters. The explicit dynamic analysis software LS-DYNA has been used to simulate the slotted cartridge blasting in the mudstone, sandstone, and granite with different strengths in order to reveal the effect of rock strength on the propagation length and velocity of the primary crack and the stress distribution characteristics in rock. The numerical results show the primary crack easily bifurcates and attain a much shorter propagation length in the mudstone with the minimum strength, and there are radial cracks appearing in the nonslotted direction. When rock strength rises, the propagation length, velocity, and duration of the primary crack and the concentration degree of effective stress in the slotted direction will all increase in the sandstone and granite, but there is an opposite influence trend of rock strength in the stage of the initial guide crack's formation. The cracking velocity has an overall oscillation downtrend whose swing amplitude enhances clearly with the increasing rock strength, signifying the more unsteady propagation of the primary crack in the higher strength rock.
\end{abstract}

\section{Introduction}

In the tunnel excavation engineering, the drilling and blasting method is widely used, however, facing the longterm challenge to reduce the damage in surrounding rocks induced by the detonation energy. A fracture surface with high quality can help lower the cost taken to the later support engineering and speed up the construction progress. To control the outline quality of tunnel excavation, the smooth blasting method was proposed in 1950s. In the smooth blasting, the hole spacing and explosive charge are controlled accurately to achieve a smooth and flat fracture surface due to the stress field superposition in the connecting direction between adjacent holes, which limit the cracks occurring and propagation in surrounding rocks in a certain degree, but the random radial cracks are still inevitable especially in the rock with well-developed joints. Based on the features and functions of smooth blasting, the directional fracture blasting was developed by means of intensifying the effect of explosion artificially to produce directional cracks and cut through in the connecting direction of the borehole centres, improving the smooth-shaped effect greatly. Hence, the directional fracture blasting has been popularized widely in mining excavation and tunnel construction.

In order to limit the appearance and propagation of the radial cracks in the surrounding rock, the generation of the prefractured cracks before the detonation gas completely acting on the borehole wall is the key problem of the directional fractured blasting, and there have been three kinds of methods of the slotted cartridge, the shaped charge, and the cutting borehole to concentrate on the explosive energy and generate the initial guide crack. Using shaped charge 
needs to change the shape of the explosive which is unsafe and even violating the safety rules in some situations and is not so convenient. For the directional fracture blasting in the cutting hole, artificial V-shaped grooves need to be made with special tools in each peripheral borehole ahead, and this may decrease the construction speed because of the cumbersome works especially in the rock with high strength. In contrast, the slotted cartridge is able to produce a jet to not only generate the initial guide crack but also protect the borehole wall by preventing the detonation gas into the preexisting fissures. At the same time, the slotted cartridge does not need to modify the shape of explosives or boreholes, but to only add a slotted pipe easy to install outside the explosive, bringing a more broad range of application. Many researchers have carried out a large amount of study about the blasting mechanism of the directional fracture technology with slotted cartridge.

In 1976, the slotted cartridge was firstly introduced to blasting engineering by scholars [1] of USA, producing the cracks of specified direction and quantity which achieved the purpose of directional fracture. The essence of slotted cartridge blasting is to open the slots of different angles and different quantities on a pipe with certain density and strength outside the explosive [2] and enable the control on the fracture direction of the blasting medium by changing the distribution of slot-controlled blasting stress field and the quasistatic effect of detonation gas to the (borehole) medium. Wang, Yue, and Yang et al. [2-4] used the digital laser dynamic caustics testing method to analyze the dynamic fracture effect of the blasting detonation crack and examine the propagation mechanism through some important characteristic parameters including the crack displacement, the propagating speed, the accelerated speed, and the stress intensity factor of the primary crack tip. Dai et al. [5] investigated the factors impacting the slot width in a slotted pipe by the numerical method, providing the theoretical certification for slot width taken as $3 \sim 5 \mathrm{~mm}$. Luo and Man et al. $[6,7]$ studied the initiation mechanism of the initial guide crack and its criterions of propagation and arrest on the basis of theories of explosive and rock fracture mechanics, and the smooth blasting effect was improved in the site blasting test.

Among these theoretical and experimental research on the characteristic parameters, the propagation length and velocity of the primary crack are vital specially, as the borehole spacing and directional fracture performance mainly and visually depend on the crack propagation length and velocity obviously. As discussed by Wang and Yue [2, 3], the propagation velocity of the detonation primary crack had an overall oscillation downtrend from the maximum peak $334.1 \mathrm{~m} / \mathrm{s}$; after the oscillation change, it reached the peak $282.7 \mathrm{~m} / \mathrm{s}$ for the second time when $t=125$ to $165 \mu \mathrm{s}$. The second peak occurred because the quasistatic pressure action may influence the crack propagation, which needs further discussion. Luo and Shen [6] had deduced the length of primary cracks under the directional fracture blasting with shape charge but not slotted cartridge; furthermore, the influence of the crush zone volume on the pressure variation of detonation gas had not been taken into account. Thereby, it is imperative to deeply study the propagation length and velocity of the primary crack in slotted cartridge blasting.

With the popularization of slotted cartridge in practice blasting engineering, the research on the influence of rock property on the slotted cartridge blasting effect has a significant engineering value due to the "zero effect" of slotted cartridge blasting applied in the rock with some special properties in engineering practice. The universal adaptability of the data and conclusion from lab and field tests is limited by the detonation condition with high temperature, high pressure, and high speed; on the contrary, numerical simulation is an available method to examine the influence mechanism of rock property on the blasting effect with slotted cartridge. But the current numerical simulation methods are difficult to characterize all the properties of rock accurately; in addition, the existing numerical simulation research on the factors affecting the blasting effect with slotted cartridge mainly focused on the influence of ground stress condition $[8,9]$, decouple coefficient, slot width, and thickness of the slotted pipe [10-12]. Therefore, it is theoretically worth considering to separately study the effect of rock strength on the effect of slotted cartridge blasting using numerical simulation.

This paper plans to conduct the theoretical research on the influence mechanism of rock strength based on the propagation length of primary cracks in the directional fracture blasting using slotted cartridge on the basis of the theories of explosive mechanics and rock fracture mechanics. Then, the finite element analysis software ANSYS/ LS-DYNA is used to simulate the slotted cartridge blasting in the model of mudstone, sandstone, and granite, respectively. The expansion velocity and length of the primary crack and the stress distribution in the rock with different strengths are emphatically discussed, which will offer the theoretical basis and guidance for the parameter design of the slotted cartridge blasting in the rock with different strengths.

\section{Influence Mechanism of Rock Strength on the Propagation of Directional Cracks}

2.1. Analysis of Slotted Cartridge Blasting Process. The rock region under the explosive loading is divided into crush zone, crack zone, and vibration zone in traditional blasting theory. Relatively, due to the slotted pipe, a gas flow with high energy density will be induced to the slotted direction in slotted cartridge blasting, as shown in Figure 1, whose fracture characteristics are different from the normal blasting without slotted cartridge.

Combined with traditional blasting theory and the structure characteristics of slotted cartridge, it is predicted that the process of slotted cartridge blasting can be divided into following three stages: (1) After the explosive initiation, detonation gas will be extruded outward along with the slotted direction and converged into a gas jet flow with high temperature and high pressure. Meanwhile, the shock wave in the slotted direction should be stronger than that in the nonslotted direction because of the reflect effect of the slotted pipe with a higher density than explosive. (2) The wall of borehole in the slotted direction will be impacted and 


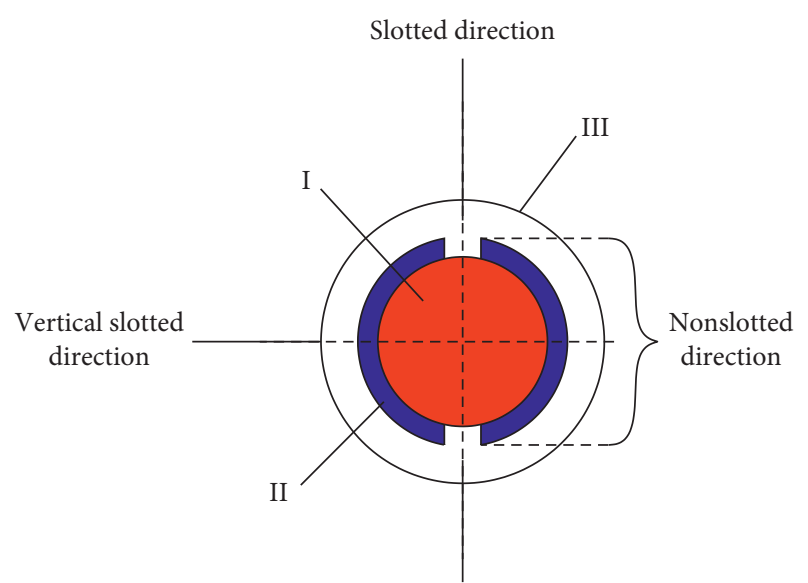

Slotted direction

Figure 1: The charge structure in the directional fracture blasting with slotted cartridge: (I) explosive; (II) slotted pipe; (III) borehole.

eroded by the gas jet and shock wave, in which the initial guide crack will form. At the same time, the detonation gas will push the slotted pipe to expand outward with continuous breaks. (3) The initial guide crack tip will continue propagating as a primary crack under the subsequent explosion stress wave and the quasistatic effect of detonation gas until the primary crack is arrested, accompanied by a little range of crushed rock (crush zone) in the nonslotted direction due to the extreme pressure of shock wave and high-pressure detonation gas, though the slotted pipe and the air buffer between the slotted pipe and borehole wall have relieved the impact on the wall of borehole as much as possible. If the circumferential tensile stress of the internal rock in the nonslotted direction caused by the radial pressure of detonation gas is greater than the uniaxial tensile strength of rock, the radial crack in the nonslotted direction will be generated against the purpose of directional fracture blasting.

Based on the analysis above, there are two evaluation aspects about the effect of the slotted cartridge blasting clearly: the primary crack has enough propagation length in the slotted direction, and few radial cracks appear in the nonslotted direction.

2.2. Calculation of the Length of the Initial Guide Crack. Generally, the generation of the initial guide crack is only subject to the tensile failure and shear failure. Here, the tensile failure criterion condition was selected for the calculation of the propagation length of the initial guide crack considering that tensile strength of rock is smaller than shear strength in general. The criterion condition of tension breaking fracture is expressed by the following equation:

$$
\sigma_{\theta}>\sigma_{\mathrm{td}} \text {, }
$$

where $\sigma_{\theta}$ is the maximum circumferential tensile stress and $\sigma_{\mathrm{td}}$ is the dynamic uniaxial tensile strength of rock, which is approximately equal to the uniaxial tensile strength $\sigma_{\mathrm{t}}$.

The relation between circumferential tensile stress and radial stress is expressed by the following equation:

$$
\sigma_{\theta}=\frac{\sigma_{\mathrm{r}} \mu}{1-\mu}
$$

where $\mu$ is Poisson's ratio of rock and $\sigma_{\mathrm{r}}$ is the radial stress in the rock with borehole wall.

According to equations (1) and (2), for the generation of the initial guide crack, the radial stress on the wall of borehole $\sigma_{\mathrm{r}}$ must be made to meet the following equation:

$$
\sigma_{\mathrm{r}}>\frac{\sigma_{\mathrm{td}}(1-\mu)}{\mu} \text {. }
$$

Suppose the borehole has been filled with detonation gas and the crush zone just starts to be generated while the length of the initial guide crack has reached the maximum $a_{0}$ and $p_{0}$ is the gas pressure in the borehole after the complete formation of initial guide crack. Through elastic theory, the radial stress component $\sigma_{\mathrm{r}}$ can be approximately obtained by $a_{0}$ and $p_{0}$ as follows [13]:

$$
\sigma_{\mathrm{r}}=p_{0}\left(\frac{r_{\mathrm{b}}}{r_{\mathrm{b}}+a_{0}}\right)^{2},
$$

where $r_{\mathrm{b}}$ is the radius of the borehole.

Therefore, according to equations (3) and (4), the calculation of the maximum propagation length of the initial guide crack is expressed by the following equation:

$$
a_{0}=r_{\mathrm{b}}\left(\sqrt{\frac{\mu p_{0}}{(1-\mu) \sigma_{\mathrm{td}}}}-1\right) \text {. }
$$

2.3. Calculation of the Length of Primary Cracks. According to the theory of rock fracture mechanics, under the quasistatic $(p)$ effect, the stress intensity factor $K_{\mathrm{I}}$ of the crack tip is expressed by the following equation:

$$
K_{\mathrm{I}}=p F \sqrt{\pi\left(a+r_{\mathrm{b}}\right)},
$$

where $a$ is the length of the crack and $F$ is the coefficient of correction of the stress intensity factor [6] and $F=F\left[\left(a+r_{\mathrm{b}}\right) / r_{\mathrm{b}}\right]$.

Suppose $K_{\text {IC }}$ is the fracture toughness of rock, the crack will expand if the following equation is met:

$$
p \geq \frac{K_{\mathrm{IC}}}{F \sqrt{\pi\left(a+r_{\mathrm{b}}\right)}} .
$$

As for the directional fracture blasting with slotted cartridge, the detonation product gas is the drive of the expansion of the primary cracks. According to equation (7), to make the initial guide crack continue expansion after it was generated completely, the gas pressure $p_{0}$ at this moment must be satisfied:

$$
p_{0} \geq \frac{K_{\mathrm{IC}}}{F \sqrt{\pi\left(a_{0}+r_{\mathrm{b}}\right)}} .
$$

Assume explosive detonation is an instantaneous process, in which there is no thermal exchange between the explosion gas and the surrounding rock. Therefore, the 
detonation gas expansion is regarded as an isentropic process, and the initial volume of the detonation gas is equal to the volume of the charge $V_{\mathrm{c}}$ [6]. The gas pressure at any instant in the borehole is expressed by the following equation:

$$
p=p_{k}\left(\frac{p_{\mathrm{w}}}{p_{k}}\right)^{r / k}\left(\frac{V_{\mathrm{c}}}{V}\right)^{r},
$$

where $p$ is the instantaneous explosive gas pressure; $k$ and $r$ are isentropic index and adiabatic index, $k=3$ and $r=1.4 ; p_{k}$ is the critical pressure and $p_{k}=200 \mathrm{MPa}[6] ; V$ is the gas volume when the pressure is $p ; p_{\mathrm{w}}$ is the mean detonation pressure and $p_{\mathrm{w}}=\rho_{0} D^{2} / 2(1+k)$; and $\rho_{0}$ and $D$ are the density and detonation velocity of charge, respectively.

According to the assumption about $a_{0}$ and $p_{0}$ mentioned earlier, during the complete formation of the initial guide crack, suppose the stemming has not been moved, the volume of the explosive gas composes of the borehole volume and the volume of two initial guide cracks. Then, when the initial guide crack has formed, the gas pressure $p_{0}$ is calculated by the following expression combined with the equation of adiabatic expansion:

$$
\begin{aligned}
p_{0} & =p_{k}\left(\frac{p_{\mathrm{w}}}{p_{k}}\right)^{r / k}\left(\frac{V_{\mathrm{c}}}{V_{\mathrm{b}}+2 V_{0}}\right)^{r}, \\
V_{\mathrm{b}} & =\frac{1}{4} \pi d_{\mathrm{b}}^{2}\left(l_{\mathrm{b}}-l_{\mathrm{s}}\right),
\end{aligned}
$$

where $V_{\mathrm{b}}$ is the initial volume of borehole; $V_{0}$ is the volume of one initial guide crack, which may be approximately calculated by the maximum length of the initial guide crack, slot width of slotted pipe, and the charge length; $d_{\mathrm{b}}$ is the diameter of borehole; $l_{\mathrm{b}}$ is the borehole length; and $l_{\mathrm{s}}$ is the stemming length.

Therefore, the maximum length of initial guide crack $a_{0}$ can be obtained from equations (5), (10), and (11).

Similarly, the gas pressure $p_{\mathrm{m}}$ while the primary crack is arrested is obtained by the following equation:

$$
\begin{aligned}
& p_{\mathrm{m}}=p_{k}\left(\frac{p_{\mathrm{w}}}{p_{k}}\right)^{r / k}\left(\frac{V_{\mathrm{c}}}{V_{\text {crush }}+V_{\mathrm{s}}+2 V_{\mathrm{m}}}\right)^{r}, \\
& V_{\mathrm{s}}=\frac{1}{4} \pi d_{\mathrm{b}}^{2} l_{\mathrm{s}},
\end{aligned}
$$

where $V_{\mathrm{s}}$ is the volume of the stemming and $V_{\mathrm{m}}$ is the volume of one primary crack as the primary crack is arrested. Suppose $\bar{\delta}$ is the mean width of the primary crack which is approximately equal to the slot width $\left(\delta_{\mathrm{w}}\right)$ of the slotted pipe, then $V_{\mathrm{m}}$ is expressed approximately as $V_{\mathrm{m}}=a_{\mathrm{m}} \bar{\delta} l_{\mathrm{b}} \approx$ $a_{\mathrm{m}} \delta_{\mathrm{w}} l_{\mathrm{b}}$ :

$$
V_{\text {crush }}=\frac{1}{4} \pi D_{\text {crush }}^{2}\left(l_{\mathrm{b}}-l_{\mathrm{s}}\right)
$$

where $V_{\text {crush }}$ is the crush zone volume, $D_{\text {crush }}$ is the crush zone diameter, $l_{\mathrm{b}}$ is the borehole length, and $l_{\mathrm{s}}$ is the stemming length.
According to the research of Dai [14], $D_{\text {crush }}$ is calculated by the following equation in the decouple charge condition:

$$
D_{\text {crush }}=\left(\frac{\rho_{0} D^{2} n K_{\mathrm{d}}^{-2 r} l_{\mathrm{e}} B}{8 \sqrt{2} \sigma_{\mathrm{cd}}}\right)^{1 / \alpha} d_{\mathrm{b}} \text {. }
$$

In the couple charge condition, the crush zone volume $D_{\text {crush }}$ is

$$
\begin{aligned}
D_{\text {crush }} & =\left(\frac{\rho_{0} D^{2} A B}{4 \sqrt{2} \sigma_{c d}}\right)^{1 / \alpha} d_{\mathrm{b}}, \\
A & =\frac{2 \rho_{\mathrm{c}} C_{\mathrm{p}}}{\rho_{\mathrm{c}} C_{\mathrm{p}}+\rho_{0} D}, \\
B & =\left[(1+b)^{2}+1+b^{2}-2 \mu_{\mathrm{d}}\left(1-\mu_{\mathrm{d}}\right)(1-b)^{2}\right]^{1 / 2},
\end{aligned}
$$

where $\sigma_{c d}$ is the dynamic uniaxial compressive strength of rock and $\sigma_{\mathrm{cd}}=n \sigma_{\mathrm{c}} ; \sigma_{\mathrm{c}}$ is the uniaxial compressive strength of rock; $n=10$ is the amplifying coefficient of gas pressure impact on the wall of rock; $\alpha$ is the attenuation exponent of shock wave load and $\alpha=2+\left(\mu_{\mathrm{d}} / 1-\mu_{\mathrm{d}}\right) ; b$ is the lateral stress coefficient and $b=\mu_{\mathrm{d}} /\left(1-\mu_{\mathrm{d}}\right) ; \mu_{\mathrm{d}}$ is dynamic Poisson's ratio of rock; $K_{\mathrm{d}}$ is the decouple coefficient; $\rho_{\mathrm{c}}$ is the density of rock; $C_{\mathrm{p}}$ is the $P$-wave velocity of rock; and $d_{\mathrm{b}}$ is the diameter of borehole.

When the primary crack is arrested, the following equation is met:

$$
K_{\mathrm{IC}}=p_{\mathrm{m}} F \sqrt{\pi\left(a_{\mathrm{m}}+r_{\mathrm{b}}\right)}
$$

Combination of equations (12)-(19), the maximum length of the primary crack can be calculated. As [15-17] shows, the number of the I-type fracture toughness $K_{\text {IC }}$ of rock has a positive proportional relationship with the number of the uniaxial tensile strength $\sigma_{\mathrm{t}}$ of rock, and Zhang [18] had found that the numerical relation between the I-type fracture toughness $K_{\text {IC }}$ and the uniaxial tensile strength $\sigma_{\mathrm{t}}$ could be expressed as $\sigma_{\mathrm{t}}=6.88 K_{\mathrm{IC}}$; hence, set

$$
K_{\mathrm{IC}}=K\left(\sigma_{\mathrm{t}}\right) \text {. }
$$

On the basis of equations (12)-(19), it is clear that the gas pressure $p_{m}$ when the primary crack was arrested is determined by the uniaxial compressive strength $\sigma_{\mathrm{c}}$ of rock and the maximum length $a_{\mathrm{m}}$ of the primary crack with the certain charge structure and explosive parameters in the slotted cartridge blasting; thus, set

$$
p_{\mathrm{m}}=P\left(\sigma_{\mathrm{c}}, a_{\mathrm{m}}\right) \text {. }
$$

According to equations (19)-(21), the maximum length $a_{\mathrm{m}}$ of the primary crack is related to the rock strength parameters (the uniaxial compressive strength and the uniaxial tensile strength), by the following equation:

$$
K\left(\sigma_{\mathrm{t}}\right)=P\left(\sigma_{\mathrm{c}}, a_{\mathrm{m}}\right) F \sqrt{\pi\left(a_{\mathrm{m}}+r_{\mathrm{b}}\right)} .
$$

Here, it is difficult to directly resolve the inverse solution of $a_{\mathrm{m}}$ by equation (22). However, qualitative analysis of the relation equation above indicates that $P\left(\sigma_{\mathrm{c}}, a_{\mathrm{m}}\right)$ will increase 
as $\sigma_{\mathrm{c}}$ increases but decrease as $a_{\mathrm{m}}$ increases, and the influence of increasing $\sigma_{\mathrm{c}}$ on $P\left(\sigma_{\mathrm{c}}, a_{\mathrm{m}}\right)$ is much stronger than that of increasing $\sigma_{\mathrm{t}}$ on $K\left(\sigma_{\mathrm{t}}\right)$ in the same kind of rock. Therefore, the maximum length of primary cracks $a_{\mathrm{m}}$ will increase to meet equation (22), when the rock strength parameters $\left(\sigma_{\mathrm{c}}\right.$ and $\left.\sigma_{\mathrm{t}}\right)$ rise.

\section{Numerical Simulation of the Slotted Cartridge Blasting in the Rock with Different Strengths}

3.1. Finite Element Model. It was planned to conduct three simulations on the slotted cartridge blasting in the rock with three different strengths; the rock strength was changed, while other parameters were unchanged every time. A plateshaped model with a half borehole was established according to the axial symmetry of the model, whose plane view size was $120 \mathrm{~cm} \times 60 \mathrm{~cm} \times 0.1 \mathrm{~cm}$, and there was only one $3 \mathrm{D}$ element in the direction of thickness. The model used was SOLID164 element, and the mapped mesh method was applied to reduce the calculating error. For the further simplified model, displacement constraint in the direction of thickness was applied to all the nodes. Thereby, the simulation was changed to a 2-dimensional subject. The boundary condition [19] is showed as Figure 2(a), where the other three boundaries except the symmetry boundary were set as the nonreflecting boundary condition. The charge diameter was $20 \mathrm{~mm}$, the borehole diameter was $32 \mathrm{~mm}$, the thickness of the slotted pipe was $2 \mathrm{~mm}$, and the slot width was $3 \mathrm{~mm}$, as shown in Figure 2(b).

The material models of this problem included explosive, slotted pipe, air, and rock.

*MAT_HIGH_EXPLOSIVE_BURN model was used for explosive, and the JWL equation of state was chosen to describe the relation [20] between the expansion pressure and the volume of detonation gas which is defined as

$$
P=A\left(1-\frac{\omega}{R_{1} V}\right) e^{-R_{1} V}+B\left(1-\frac{\omega}{R_{2} V}\right) e^{-R_{2} V}+\frac{\omega E}{V},
$$

where $V$ is the relative volume of detonation gas; $E$ is the specific internal energy with an initial value of $E_{0}$; and $A, B$, $R_{1}, R_{2}$, and $\omega$ are the constants determined by test. The parameters of the explosive model from the water-gel explosive are shown in Table 1.

${ }^{*}$ MAT_PLASTIC_KINEMATIC model was selected for the rock for the purpose of taking into account the large strain, high strain rate, and the damage under the action of detonation load [21], combined with the *MAT_ADD_EROSION model containing the thresholds of the tensile and compressive failure to acquire the macroscopic effect of fracture [22, 23]. Mudstone, sandstone, and granite were chosen as three kinds of rock with different strengths for the simulation. According to the data provided by [24], six basic parameters of these three kinds of rock including the uniaxial compressive strength $\sigma_{\mathrm{c}}$, the uniaxial tensile strength $\sigma_{\mathrm{t}}$, elasticity modulus $E$, density $\rho$, Poisson's ratio $\mu$, and the fracture toughness $K_{\mathrm{IC}}$ are determined in Table 2.
Air used the *MAT_NULL material model combined with the keyword of *EOS_LINEAR_POLYNOMIAL. The linear polynomial equation of state is linear in internal energy. It has the following form [20]:

$$
P=C_{0}+C_{1} \mu+C_{2} \mu^{2}+C_{3} \mu^{3}+\left(C_{4}+C_{5} \mu+C_{6} \mu^{2}\right) E,
$$

where $\mu=\left(\rho / \rho_{0}\right)-1, \rho$ is the current density of the material, $\rho_{0}$ is the nominal or reference density, and $E$ is the internal energy with the unit of pressure.

The linear polynomial equation of state may be used to model gas with the gamma law equation of state [20]. This may be achieved by setting: $C_{0}=C_{1}=C_{2}=C_{3}=C_{6}=0$ and $C_{4}=C_{5}=\gamma-1$, where $\gamma$ is the ratio of specific heats. In this paper, the necessary parameters $\rho_{0}$ and $\gamma$ of the air model were taken as $1.29 \mathrm{~g} / \mathrm{cm}^{3}$ and 1.4, respectively [25].

The main function of the slotted pipe lies in the retardation to the detonation product in the nonslotted direction and the protective effect to the wall of boreholes. According to a lot of test results [2], it is feasible to ignore the mechanical behaviour of the slotted pipe as its complexity. Therefore, the ideal elastoplastic material model was selected to simulate the slotted pipe, whose parameters [10] including density $\rho$, elasticity modulus $E$, yield strength $\sigma_{\mathrm{y}}$, and Poisson's ratio $\mu$ are shown in Table 3 .

Fluid-solid coupling algorithm was applied to this calculation to overcome the defect that the distorted grids of the slotted pipe, air, and rock are produced easily under the high detonation load, at the same time, in order to conveniently obtain a large amount of data of flow field after detonation as well. In this simulation, the Lagrange algorithm was performed in the slotted pipe and rock, the explosive and air were defined as the ALE space grid, the keyword *CONSTRAINED_LAGRANGE_IN_SOLID was used to set the fluid-solid coupling constraint of the fluid and solid to enable the energy transfer from the detonation product to the slotted pipe and rock [12], and the contact type between the slotted pipe and rock was surface-to-surface contact.

3.2. Analysis of the Simulation about the Slotted Cartridge Blasting Process. The simulation results of the slotted cartridge blasting in three kinds of rock, mudstone, sandstone, and granite are shown in Figures 3-5, including the primary crack propagation and pressure graph.

In the mudstone, as shown in Figure 3, the explosive in borehole was completely exploded at $t=1.89 \mu \mathrm{s}$; meanwhile, the detonation gas and shock wave firstly began to rush out of the slotted pipe along the slotted direction and then generated a powerful gas jet. The air buffer between the slotted pipe and borehole walls caused the slotted pipe to continuously expand outward, and the slotted width and angle of the slotted pipe would expand, resulting in the strength of gas jet flow continuously increased, which led to the continuous damage on the rock with borehole wall in the slotted direction until the slotted pipe just contacted with the borehole wall at $t=6 \mu \mathrm{s}$ as a symbol that the initial guide crack had formed completely by the strong gas jet. Later, the initial guide crack continued to propagate called as the primary crack under the "wedge effect" of the detonation 


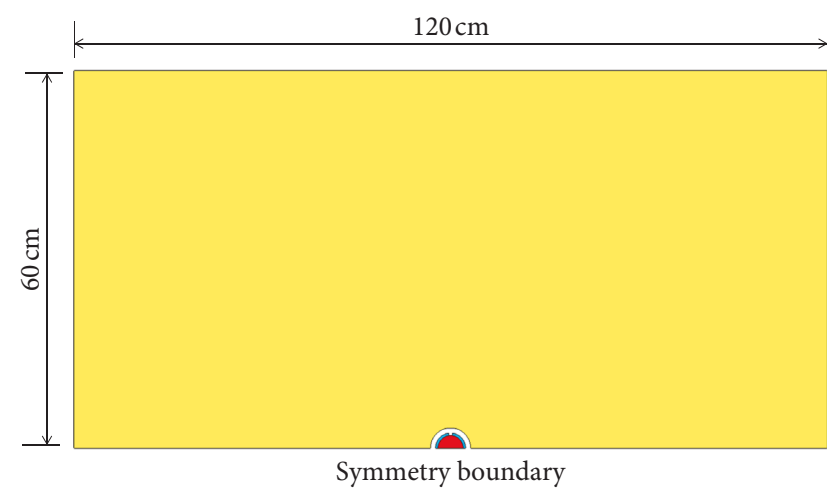

(a)

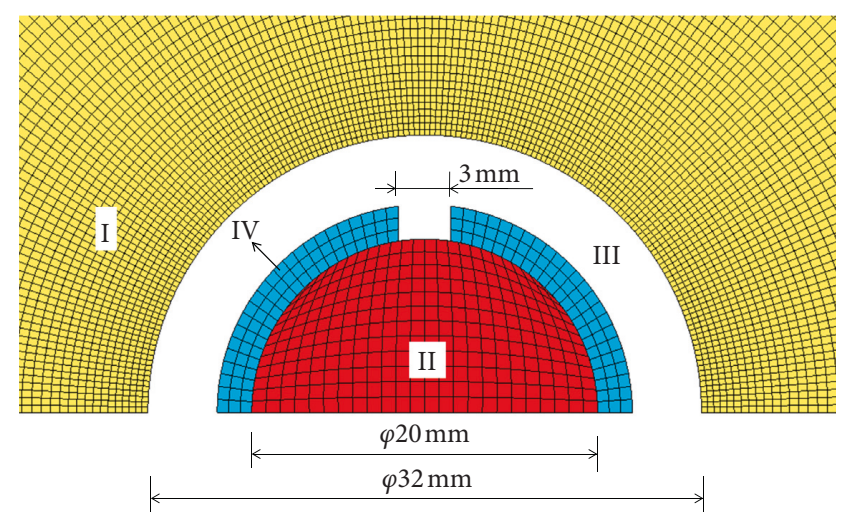

(b)

FIGURE 2: Finite element model: (I) rock; (II) explosive; (III) air; (IV) slotted pipe.

TABle 1: Parameters of explosives.

\begin{tabular}{lccccccc}
\hline$\rho\left(\mathrm{g} \cdot \mathrm{cm}^{-3}\right)$ & $D\left(\mathrm{~m} \cdot \mathrm{s}^{-1}\right)$ & $P_{\mathrm{CJ}}(\mathrm{GPa})$ & $A(\mathrm{GPa})$ & $B(\mathrm{GPa})$ & $R_{1}$ & $R_{2}$ & $\omega$ \\
\hline 1.1 & 3200 & 3.5 & 214 & 18 & 4.15 & 0.95 & 0.13 \\
\hline
\end{tabular}

TABle 2: Physical and mechanical parameters of rock.

\begin{tabular}{lcccccc}
\hline Rock & $\rho\left(\mathrm{g} \cdot \mathrm{cm}^{-3}\right)$ & $E(\mathrm{GPa})$ & $\sigma_{\mathrm{c}}(\mathrm{MPa})$ & $\sigma_{\mathrm{t}}(\mathrm{MPa})$ & $\mu$ & $K_{\mathrm{IC}}\left(\mathrm{MPa} \cdot \mathrm{m}^{1 / 2}\right)$ \\
\hline Mudstone & 2.45 & 17.0 & 30 & 2.7 & 0.21 & 0.30 \\
Sandstone & 2.5 & 30.4 & 58 & 6.5 & 0.22 & 0.68 \\
Granite & 2.8 & 55.0 & 102 & 10.5 & 0.27 & 1.19 \\
\hline
\end{tabular}

TABLe 3: Parameters of slotted pipe.

\begin{tabular}{lccc}
\hline$\rho\left(\mathrm{g} \cdot \mathrm{cm}^{-3}\right)$ & $E(\mathrm{GPa})$ & $\sigma_{\mathrm{y}}(\mathrm{MPa})$ & $\mu$ \\
\hline 1.4 & 3.2 & 60 & 0.36 \\
\hline
\end{tabular}

gas, along with severe damage and crush of the rock with borehole wall within a certain range caused by the much more intense compressive pressure of the gas than the uniaxial compressive strength of the mudstone. At $t=60 \mu \mathrm{s}$, the primary crack had branched in two, and the cracks in the nonslotted direction had appeared and then expanded gradually. At $t=300 \mu \mathrm{s}$, the cracks had been arrested absolutely with an unsatisfactory effect of directional fracture due to the obvious branch of the primary crack and the expansion of the cracks in the nonslotted direction.

In the sandstone, the explosive was completely blasted at $t=1.89 \mu \mathrm{s}$, as shown in Figure 4(a). The initial guide crack was generated under the strong impact of the detonation gas jet burst out of the slot at $t=6 \mu \mathrm{s}$. The rock with borehole wall was subject to the high pressure of detonation gas and then crushed along with further propagation of the initial guide crack (the primary crack). At $t=60 \mu \mathrm{s}$, the primary crack had not branched, there were no other cracks in the nonslotted direction, and the volume of borehole was much smaller than that in the mudstone. At $t=300 \mu \mathrm{s}$, when the cracks had been arrested fully, satisfactory results with a directional primary crack of $48.38 \mathrm{~cm}$ in length were achieved.
In the granite, as shown in Figure 5, the explosive was completely exploded at $t=1.89 \mu \mathrm{s}$. The initial guide crack with obvious shear failure was generated by the gas jet, while the slotted pipe just contacted with borehole wall at $t=6 \mu \mathrm{s}$. At $t=60 \mu \mathrm{s}$, compared with the result in the sandstone, the primary crack had not branched, and no cracks had appeared in the nonslotted direction as well, but the length of the primary crack was distinctly longer which means a faster propagation velocity of the primary crack in the granite. Finally, the primary crack had been arrested almost with a propagation length of $57.79 \mathrm{~cm}$ at $t=300 \mu \mathrm{s}$, as a perfect directional fracture result.

The comparative study based on the simulation results above sufficiently explained the process of the initial guide crack's generation and the primary crack's propagation, which shows that, after the explosive in borehole was completely exploded, the detonation gas and shock wave firstly burst out of the slotted pipe along the slotted direction and then formed a powerful gas jet impacting the borehole wall and resulting in the generation of the initial guide crack accompanied by the slotted pipe just contacting with the borehole wall. Later, the rock with borehole wall was crushed by the powerful pressure of the detonation product where is called as the crush zone. Meanwhile, the initial guide crack continued to expand called as the primary crack subject to the quasistatic effect of detonation gas until the primary crack is arrested. 


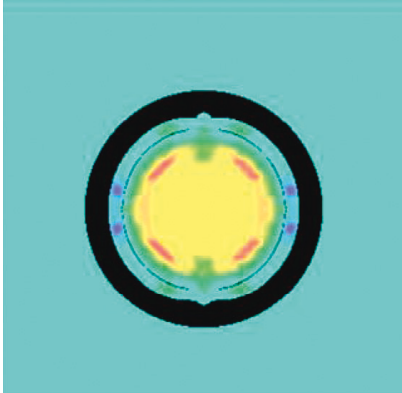

(a)

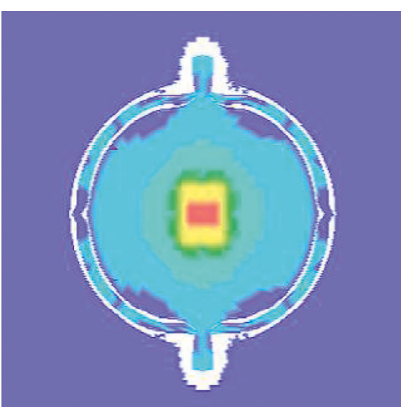

(b)

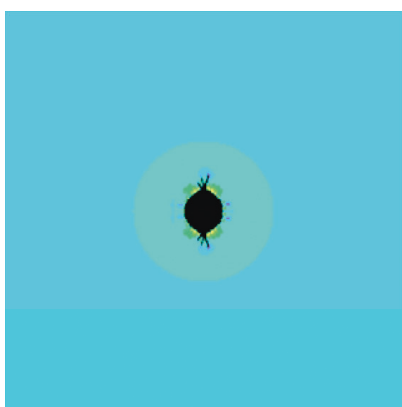

(c)

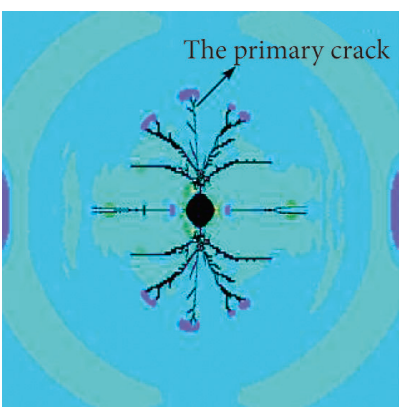

(d)

Figure 3: The initiation and propagation of the directional crack in the mudstone: (a) $t=1.89$; (b) $t=6$; (c) $t=60$; (d) $t=300$.

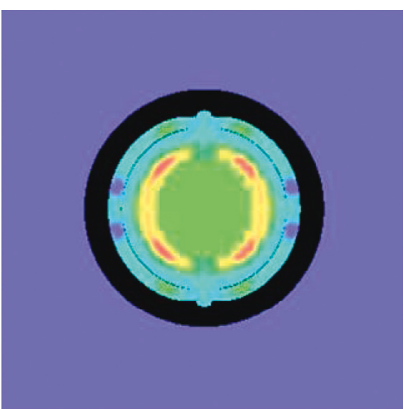

(a)

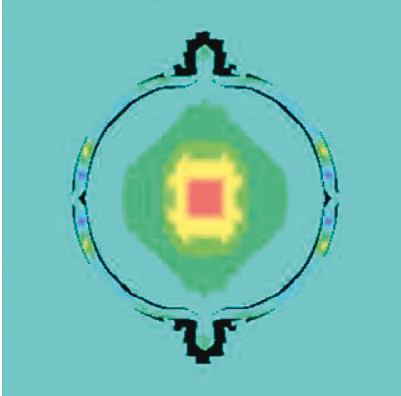

(b)

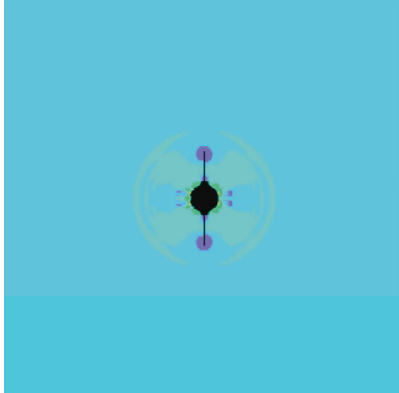

(c)

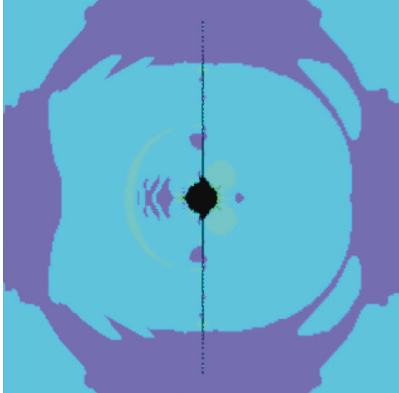

(d)

FIgURE 4: The initiation and propagation of the directional crack in the sandstone: (a) $t=1.89$; (b) $t=6$; (c) $t=60$; (d) $t=300$.

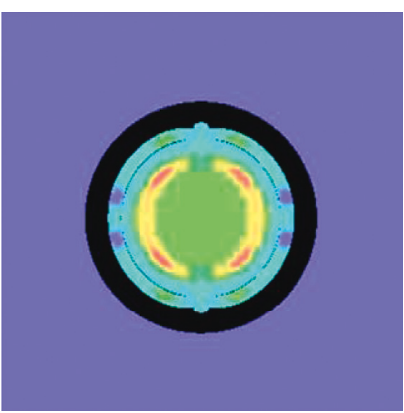

(a)

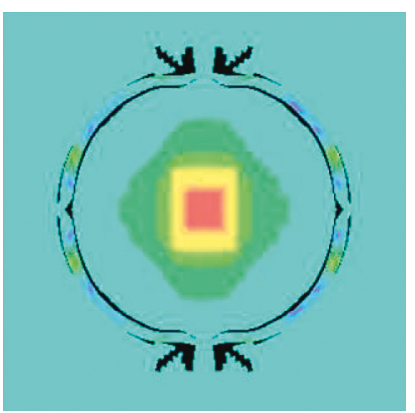

(b)

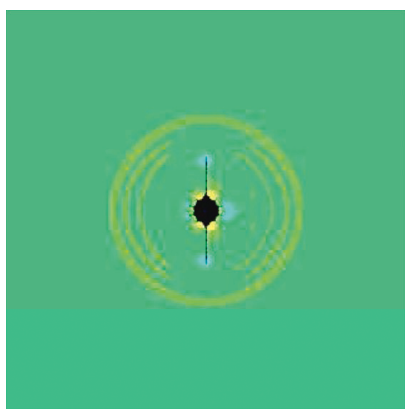

(c)

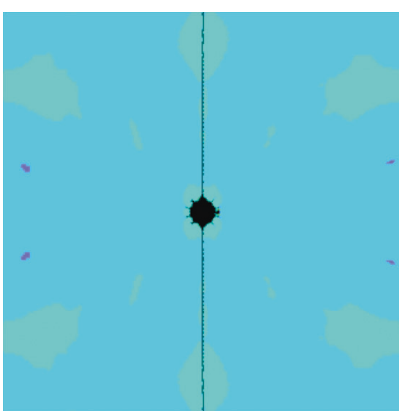

(d)

FIgURE 5: The initiation and propagation of the directional crack in the granite: (a) $t=1.89$; (b) $t=6$; (c) $t=60$; (d) $t=300$.

Apparently, the variations of rock strength greatly affected the directional fracture effect, especially the propagation length and velocity of the primary crack. In the mudstone, because uniaxial compressive strength of the rock was so weak, a large amount of detonation energy was directly consumed in the rock crush under the shock wave and the detonation gas, making the detonation gas pressure much lower while the primary crack was expanding. In addition, the volume of borehole was larger than that in the rock with higher strength, which means the detonation gas pressure decreased further, leading to the drive shortage, easy branch, and the shortest length and lowest velocity of the primary crack's propagation. In the nonslotted direction, because of the lower uniaxial tensile strength than the circumferential tensile stress arising from the detonation gas, radial cracks appeared in the borehole wall, against the directional fracture effect. In the sandstone, the uniaxial compressive strength of rock was higher, causing the energy used for the rock compression of borehole wall to decline massively, the volume of borehole was smaller, and the quasistatic effect of detonation gas applied to the primary crack was much stronger than that in the mudstone. Therefore, no bifurcation formed, meaning more powerful drive leaved and the propagation length and velocity of the primary crack would be much larger compared with that in the mudstone. In the granite, the higher uniaxial compressive strength made more energy concentrated on the propagation of the primary crack, resulting in the faster 
propagation velocity and longer propagation length than that in the sandstone, and no radial cracks appeared in the nonslotted direction though the pressure of the detonation gas in borehole was higher than that in the mudstone.

The analysis results above demonstrate that the initial guide crack is generated by the detonation gas jet, and the further propagation is notably influenced by the rock strength. In the mudstone, the primary crack is likely to branch with a greatly short propagation length, and radial cracks will appear in the nonslotted direction very probably. The higher the rock strength, the more the energy concentrated in the slotted direction, the faster the primary crack's expansion, and the longer the propagation length.

3.3. Primary Crack Propagation Characteristics. There were several developed cracks around the borehole wall in the mudstone, as shown in Figure 3(d), and the longest one in the slotted direction was marked as the primary crack in the mudstone to be compared with that in the sandstone and granite. If $t \leq 10 \mu \mathrm{s}$, the $y$ coordinates at the primary crack tip when $t=0,4,6$, and $10 \mu \mathrm{s}$, respectively, were taken as the primary cracking length, considering the initiation progress of the initial guide crack in Figures 3-5. If $t>10 \mu \mathrm{s}$, the $y$ coordinates at the primary crack tip with a time interval of $10 \mu$ s were taken as the primary cracking length. Then, the average velocity of crack propagation in each time interval can be obtained by the displacement of the crack tip at each selected instantaneous moment, as shown in Figures 6 and 7.

Figure 6 shows the relation curve of the primary cracking length changing with time. The variation of the slop of the curve means the oscillation of the crack propagation velocity. In Figure 6(a), from $t=0 \mu \mathrm{s}$, when the explosive was detonated completely, the gas jet in the slotted direction was generated and rushed into the air buffer until the initial guide crack started to occur when $t=4 \mu \mathrm{s}$, and then the length of the initial guide crack increased gradually subject to the gas jet until the borehole was filled with detonation gas. At this point, the initial guide crack was fully formed with lengths of $4.939 \mathrm{~mm}, 4.079 \mathrm{~mm}$, and $3.271 \mathrm{~mm}$ in the mudstone, sandstone, and granite, respectively, when $t=6 \mu \mathrm{s}$. It is noted that the length of the initial guide crack in the mudstone was longest and the cracking length decreased with the enhancing rock strength which signified the average propagation velocity of the initial guide crack in the time interval of its generation process from $t=4 \mu \mathrm{s}$ to $t=6 \mu \mathrm{s}$, having a negative correlation with the rock strength as shown in Figure 7. But after $t=6 \mu \mathrm{s}$, the velocity of the primary crack in the higher strength rock became faster, so the length of the primary crack in the granite had risen to the largest, followed by sandstone and mudstone in the last when $t=30 \mu \mathrm{s}$, as shown in Figure 6(b). Then, the crack propagation velocity maintained a little oscillation down from the maximum peaks of $250.25 \mathrm{~m} / \mathrm{s}, 312.68 \mathrm{~m} / \mathrm{s}$, and $413.36 \mathrm{~m} / \mathrm{s}$ in the mudstone, sandstone, and granite, respectively, along with the differences of the cracking length in three kinds of rock expanding gradually. When $t=160 \mu \mathrm{s}$ to $180 \mu \mathrm{s}$, the velocity of the primary crack in mudstone, sandstone, and granite rapidly decreased in turn, leading to the slow growth in the cracking length. When $t \approx 260 \mu \mathrm{s}$, the primary crack was arrested fully with a length of $34.74 \mathrm{~cm}$, $48.38 \mathrm{~cm}$, and $57.79 \mathrm{~cm}$ in mudstone, sandstone, and granite, respectively.

During the generation of the initial guide crack, the lower the rock strength, the faster the crack propagation velocity, and the longer the cracking length which was consistent with the theoretical analysis of equation (5) whose calculations on the length of the initial guide cracks based on the parameters of the numerical model are $3.9 \mathrm{~mm}, 2.7 \mathrm{~mm}$, and $2.5 \mathrm{~mm}$ in the mudstone, sandstone, and granite, respectively. The results from theoretical calculation and simulation have the same influence tendency of rock strength on the length of the initial guide crack, though the result of theoretical calculation is smaller than that of the simulation; on account of that the gas average pressure $p_{0}$ taken for the initial guide crack process in theoretical analysis is lower than the impact pressure of the gas jet which is the true driving force for the propagation of the initial guide crack.

Overall, both the propagation length and velocity of the directional crack in the higher strength rock were larger relatively, while there is an opposite influence trend of rock strength in the stage of the initial guide crack. The cracking velocity in three kinds of rock reached the individual peak before $t=50 \mu \mathrm{s}$, followed by the swing down whose oscillation amplitude increased with the increasing rock strength clearly, signifying more unsteady propagation of the primary crack in the higher strength rock such as the granite. When $t=160 \mu$ s to $180 \mu \mathrm{s}$, the cracking velocity declined quickly in the order of rock strength, and the cracking velocity in the mudstone firstly reduces dramatically, followed by the sandstone, and then granite in the last. The duration of the crack propagation increased with the enhancing rock strength, which should be caused by the faster decrease of the gas pressure in the lower strength rock.

3.4. Comparison of the Effective Stress Distribution with Different Rock Strengths. The relation between the propagation length and velocity of the primary crack and the rock strength is subject to the influence of the rock strength on the effective stress distribution of the rock in different directions. In Figure 8(a), to study the effective stress distribution in the slotted direction in the rock with different strengths, six measuring points with an interval of $4 \mathrm{~cm}$ were taken in the slotted direction from the rock model of mudstone, sandstone, and granite, respectively, and the effective stress peak at each measuring point was shown in Figure 8(b).

Figure $8(\mathrm{~b})$ is the radial distribution of the effective stress peaks in the slotted direction in the mudstone, sandstone, and granite, showing that the closer to the centre of borehole, the higher the effective stress difference between the rock with different strengths, and the effective stress peaks increased along with the augment of the rock strength from an overall view in the slotted direction. It indicated that the slotted cartridge blasting energy concentrated in the slotted direction was highest in the granite to the benefit of the propagation of the primary crack under the same charge 


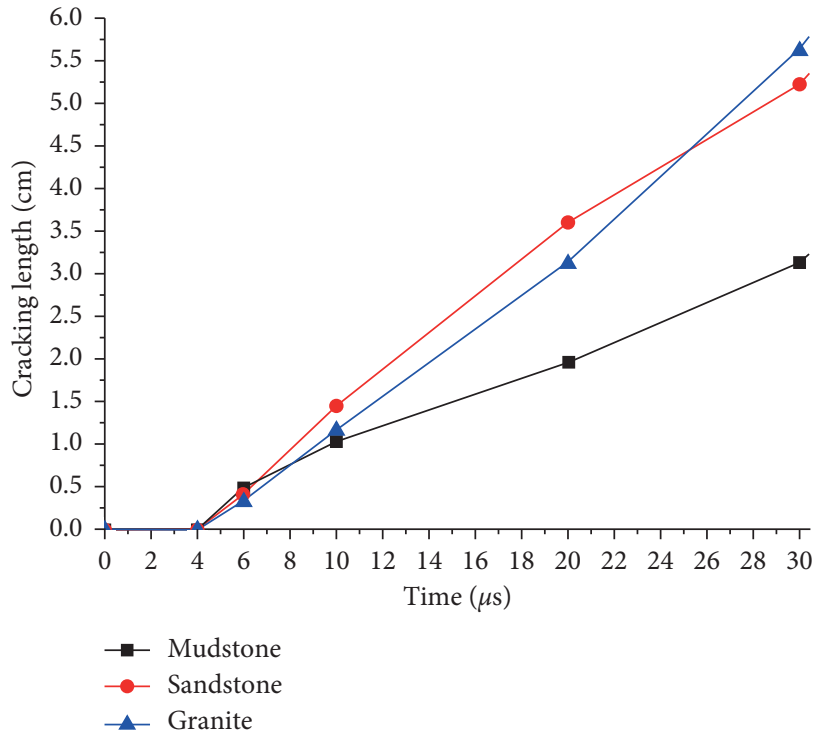

(a)

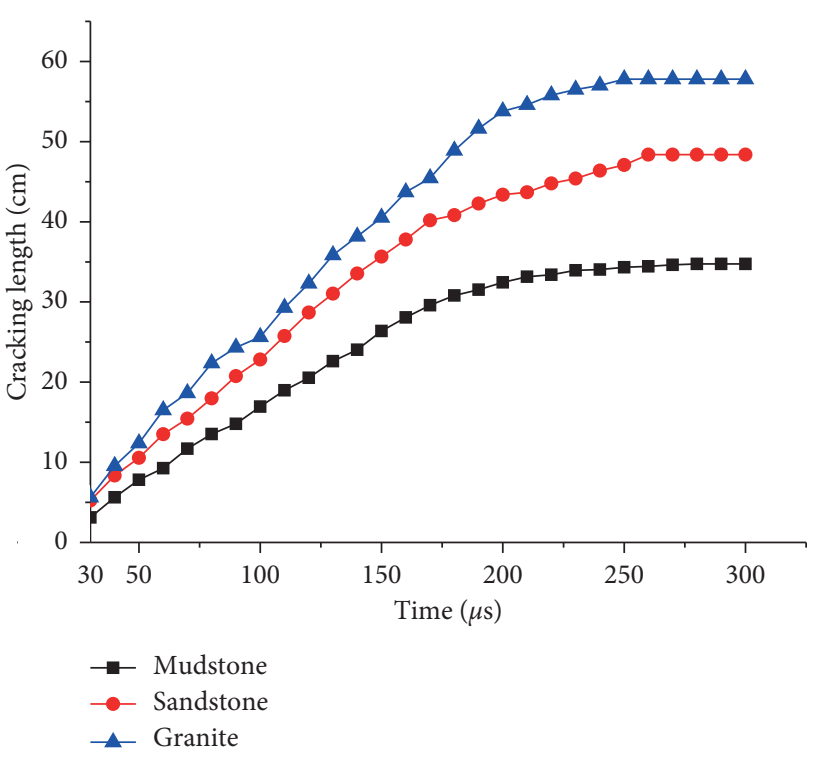

(b)

FIGURE 6: Relation between the primary cracking length and time.

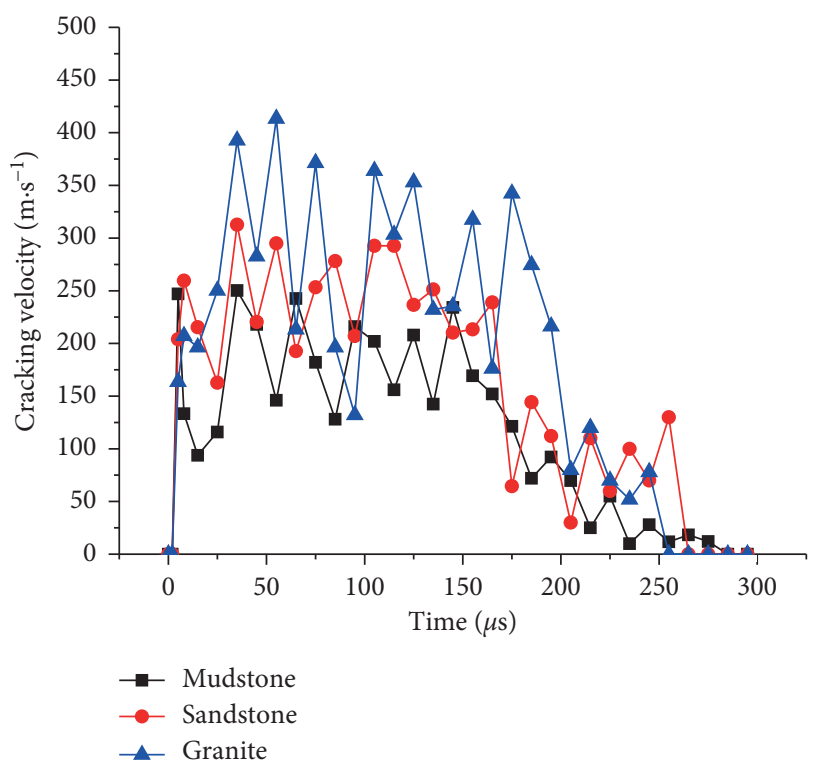

FIGURE 7: Relation between the primary cracking velocity and time.

condition, resulting in the quick decline of the cracking velocity in the order of rock strength from $t=160 \mu \mathrm{s}$ to $180 \mu \mathrm{s}$. When the rock strength is enlarged, the ratio of the detonation energy for the compression and crush of the borehole wall will decrease, more detonation energy will concentrate on the primary crack in the slotted direction and the rock zone in the nonslotted direction, the former is beneficial to enhance the propagation length and velocity of the primary crack, but the latter may cause the radial cracks in the nonslotted direction, which is bad for the directional fracture effect.

To investigate the circumferential distribution characteristics of the rock effective stress in the slotted cartridge blasting, the measuring points with an interval of $20^{\circ}$ were taken along the circumference of $8 \mathrm{~cm}$ from the explosive centre, and the effective stress on each measuring point at $t=60 \mu \mathrm{s}$ was extracted to draw a polar diagram, as shown in Figure 9. Only the data in the model of sandstone and granite were obtained because the directional fracture effect in the mudstone was too poor to contrast.

Figure 9(b) shows that, from the view of different directions, the effective stress reduced generally from the vertical slotted direction $\left(0^{\circ}\right.$ or $\left.180^{\circ}\right)$ to the adjacent slotted direction $\left(80^{\circ}\right.$ or $\left.100^{\circ}\right)$ both in the model of sandstone and granite at $t=60 \mu \mathrm{s}$, as a kind of circumferential distribution characteristics of the rock effective stress. It was resulted that when $t=60 \mu \mathrm{s}$, the primary crack had passed the measuring point where the most of detonation gas energy in the slotted direction had been consumed in the crack propagation, making the rest dynamic effect applied to the rock zone in the closer slotted direction lighter than that in the further slotted direction. From the view of different rock strengths, the effective stress in the granite was higher than that in the sandstone in the same direction. The difference of effective stress between the model of granite and sandstone increased constantly from the vertical slotted direction $\left(0^{\circ}\right.$ or $\left.180^{\circ}\right)$ to the adjacent slotted direction $\left(80^{\circ}\right.$ or $\left.100^{\circ}\right)$ where the maximum discrepancy of effective stress achieved up to 28.3 MPa. In the closer slotted direction, the detonation effect in the granite was stronger than that in the sandstone, producing a longer propagation length of the primary crack. In contrast, the effective stress difference became minimum only at $1.26 \mathrm{MPa}$ or $1.37 \mathrm{MPa}$ in the vertical slotted direction $\left(0^{\circ}\right.$ or $\left.180^{\circ}\right)$. It shows that even the radial cracks should easily appear in the nonslotted direction, especially the vertical slotted direction under the higher stress in rock caused by the higher pressure of the detonation gas in the granite compared with that in the sandstone; however, the faster 


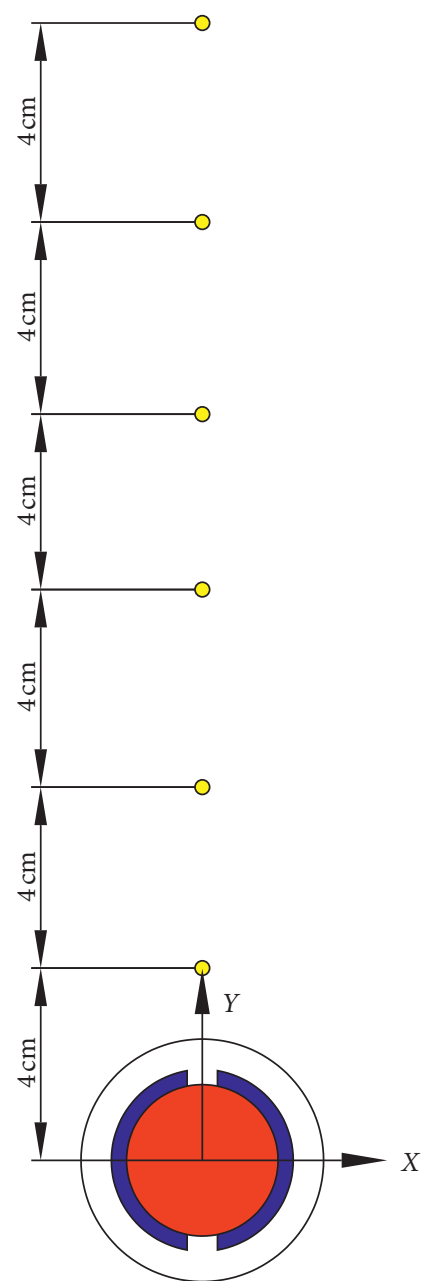

(a)

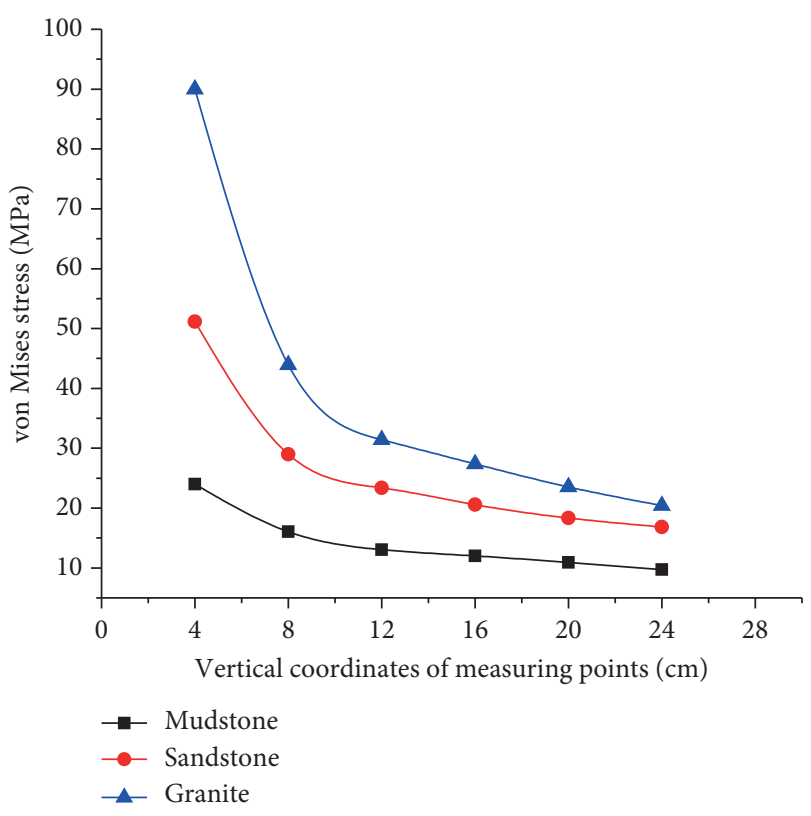

(b)

Figure 8: (a) Position of measuring points; (b) distribution of effective stress peaks in the slotted direction along the $Y$ axis in (a).

propagation velocity of the primary crack and the greater proportion of the energy in the slotted direction in the granite observably enhanced the stress relaxation in the nonslotted direction, making the effective stress discrepancy between the granite and sandstone small enough in the vertical slotted direction, and no radial cracks were generated in this direction at $t=60 \mu \mathrm{s}$ when the primary crack was expanding steadily.

\section{Discussion}

In engineering practice, the propagation length of the primary crack determines the quality of slotted cartridge blasting in the surrounding holes, and it is affected by the rock strength which is a factor beyond human control. Many other factors such as the diameter of borehole, charge structure, charge quantity, the type of explosive, and the borehole layout are controlled artificially in which the decoupling coefficient, charge density, and spacing of peripheral holes can be deemed as three most obvious parameters [2] and should be designed and determined on the basis of the factors subject to objective conditions such as the physical and mechanical properties (represented by the rock strength) of the peripheral medium, the geological condition, and construction environment.

This paper systematically discussed the effects of rock strength on the propagation length and velocity of the primary crack, which offers the theoretical basis and guidance for the parameters design of the slotted cartridge blasting in the rock with different strengths. In the too lowstrength rock such as the soft mudstone, due to the short propagation length of the primary crack and the radial cracks appearing in the nonslotted direction, the spacing of peripheral holes and the charge quantity should be reduced in order to decrease the wall-rock damage and improve the outline quality of the shaft and tunnel. In the higher strength rock, for example, the hard sandstone or granite, the propagation length, and velocity of the primary crack increase and few radial cracks form in the nonslotted direction. Therefore, it is reasonable to decline the charge quantity and add the spacing of peripheral holes appropriately compared with the normal blasting without slotted cartridge because of the reducing total charge quantity and 


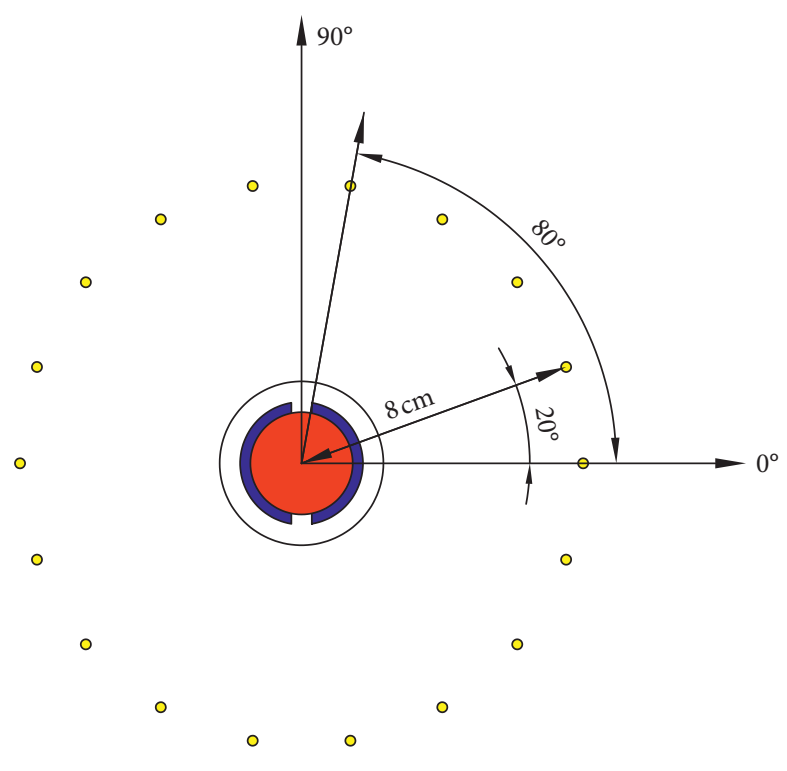

(a)

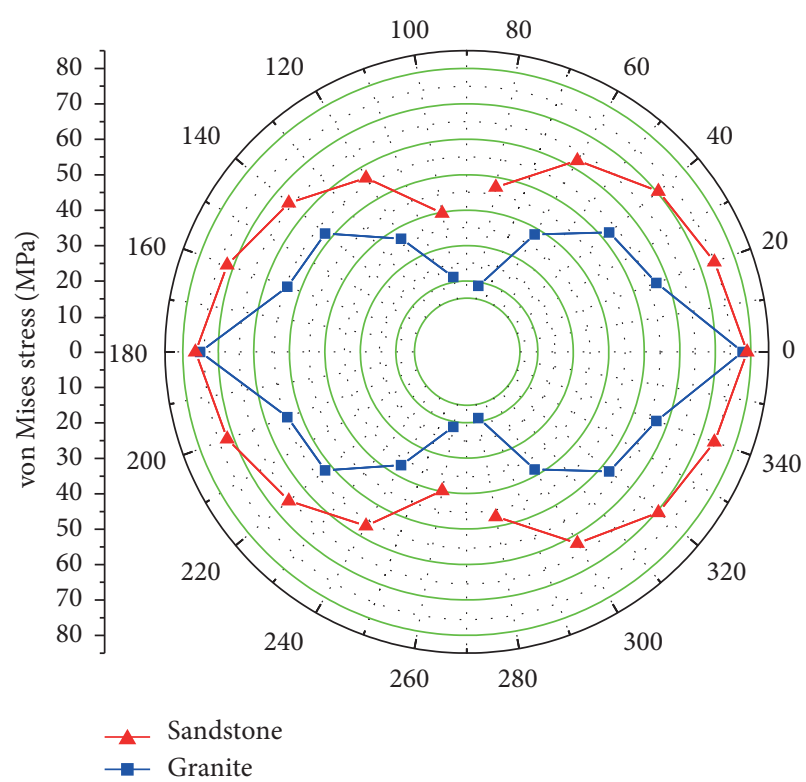

(b)

Figure 9: (a) Position of measuring points; (b) circumferential distribution of effective stress in the nonslotted direction at $t=60 \mu$ s.

the number of boreholes to relieve the blasting vibration and accelerate the excavation speed, in the meantime, guaranteeing the enough shaping effect of peripheral holes. The high efficiency and economic effect of the slotted cartridge blasting technology have been verified in the engineering practice $[7,12]$.

In addition, the influence laws of the other objective factors such as the jointing crevasse growth condition of the peripheral medium on the propagation length of the primary crack in the slotted cartridge blasting need further research with more work.

\section{Conclusions}

The theories of explosive mechanics and rock fracture mechanics were used to study the influence laws of the rock strength on the primary crack in the slotted cartridge blasting. Based on the numerical simulation results of ANSYS/LS-DYNA, the propagation length and velocity of the primary crack and the effective stress distribution characteristics under the effect of slotted cartridge blasting in the mudstone, sandstone, and granite of three different strengths were analyzed. The main conclusions of this paper are as follows:

(1) The calculation of the generation of the initial guide crack, the propagation, and arrest criterion condition of the primary crack and the maximum propagation length were deduced to propose the relation equation between the primary crack propagation length $a_{\mathrm{m}}$ and rock strength $\left(\sigma_{\mathrm{c}}, \sigma_{\mathrm{t}}\right)$, demonstrating that the final propagation length $a_{\mathrm{m}}$ increases with the increasing of rock strength $\left(\sigma_{\mathrm{c}}, \sigma_{\mathrm{t}}\right)$.

(2) The analysis of the simulation results shows that the primary crack is likely to bifurcate and gets the propagation length of $34.74 \mathrm{~cm}$ in the mudstone with too weak strength; in addition, there are radial cracks appearing in the nonslotted direction. The primary crack expands along the desired direction with a final length of $48.38 \mathrm{~cm}$ and $57.79 \mathrm{~cm}$ in the sandstone and granite, respectively.

(3) When rock strength rises, all the propagation length, velocity, and duration of the primary crack will increase in the sandstone and granite, while there is an opposite influence tend of rock strength in the stage of the initial guide crack's formation from $t=4 \mu \mathrm{s}$ to $t=6 \mu \mathrm{s}$. The cracking velocity has an overall oscillation downtrend whose swing amplitude enhances along with the increasing rock strength clearly, signifying the more unsteady propagation of the primary crack in the higher strength rock.

(4) Although the pressure of the detonation gas is higher in the model of granite, however, the faster propagation velocity of the primary crack in the granite enhances the stress relaxation in the nonslotted direction; as a result, the increase of rock strength has a weak effect on the internal effective stress of rock in the nonslotted direction, and few radial cracks are generated in this direction.

\section{Data Availability}

The data used to support the findings of this study are available from the corresponding author upon request.

\section{Conflicts of Interest}

The authors declare that there are no conflicts of interest regarding the publication of this paper. 


\section{Acknowledgments}

This work was supported by the National Fund of Nature Science of China (no. 51323004).

\section{References}

[1] W. L. Fourney, J. W. Dally, and D. C. Hollowouy, "Controlled blasting with ligamented charge holders," International Journal of Rock Mechanics and Mining Sciences \& Geomechanics Abstracts, vol. 15, no. 3, pp. 121-129, 1978.

[2] Y. Wang, "Study of the dynamic fracture effect using slotted cartridge decoupling charge blasting," International Journal of Rock Mechanics and Mining Sciences, vol. 96, pp. 34-46, 2017.

[3] Z. W. Yue, L. Y. Yang, and Y. B. Wang, "Experimental study of crack propagation in polymethyl methacrylate material with double holes under the directional controlled blasting," $F a$ tigue \& Fracture of Engineering Materials \& Structures, vol. 36, no. 8, pp. 827-833, 2013.

[4] R. Yang and Y. Wang, "Experimental study of dynamic fracture effect of blasting crack of slotted cartridge decoupling charge blasting," China Journal of Mechanics and Engineering, vol. 32, no. 7, pp. 1337-1343, 2013, in Chinese.

[5] J. Dai, D. Wang, G. Xiong et al., "Determination of slot width in a slotted pipe for directional-split blasting," Nonferrous Metals, vol. 4, pp. 110-113, 2004, in Chinese.

[6] Y. Luo and Z. Shen, "Study on orientation fracture blasting with shaped charge in rock," Journal of University of Science and Technology Beijing, Mineral, Metallurgy, Material, vol. 13, no. 3, pp. 193-198, 2006.

[7] K. Man, X. Liu, J. Wang, and X. Wang, "Directional blasting technology of slit charge for geological disposal of high-level radioactive waste," Advances in Civil Engineering, vol. 2018, Article ID 6401545, 9 pages, 2018.

[8] G. W. Ma and X. M. An, "Numerical simulation of blastinginduced rock fractures," International Journal of Rock Mechanics and Mining Sciences, vol. 45, no. 6, pp. 966-975, 2008.

[9] C. Wei, W. Zhu, Y. Bai et al., "Numerical simulation on cutting seam cartridge blasting under different in-situ stress conditions," Explosion and Shock Waves, vol. 36, no. 2, pp. 161-169, 2016, in Chinese.

[10] Y. Yu, Y. Lu, and Y. Lu, "Numerical simulation of controlled perimeter blasting and field test on the fracture zones in Guanjiao tunnel," Rock Mechanics: Achievements and Ambitions, vol. 2, pp. 57-63, 2012.

[11] B. Wu, "The initial crack formation and application research about the controlled blasting in cutting seam cartridge," Master's dissertation, Xi'an University of Science and Technology, Xi'an, China, 2014, in Chinese.

[12] L. Jiang, Mechanism and Application of Directional Fracture Blasting, China University of Mining and Technology, Beijing, China, 2010, in Chinese.

[13] Y. Xu and Q. Zong, "Theoretical analysis on the parameters of smooth blasting soft mat layer charge construction," Journal of China Coal Society, vol. 25, no. 6, pp. 610-613, 2000, in Chinese.

[14] J. Dai, "Calculation of radii of broken and crack areas in rock by a long charge explosion," Journal of Liaoning Technical University (Nature Science), vol. 2, pp. 144-147, 2001, in Chinese.

[15] K. Man and H. Zhou, "Research on dynamic fracture toughness and tensile strength of rock at different depth," Chinese Journal of Rock Mechanics and Engineering, vol. 8, pp. 1657-1663, 2010, in Chinese.
[16] B. N. Whittaker, N. Singhr, and G. Sun, Rock Fracture Mechanics: Principles, Design and Applications, Elsevier, Amsterdam, Netherlands, 1992.

[17] J. J. Wang, J. G. Zhu, C. F. Chiu, and H. Zhang, "Experimental study on fracture toughness and tensile strength of a clay," Engineering Geology, vol. 94, no. 1-2, pp. 65-75, 2007.

[18] Z. X. Zhang, "An empirical relation between mode I fracture toughness and the tensile strength of rock," International Journal of Rock Mechanics \& Mining Sciences, vol. 39, no. 3, pp. 401-406, 2002.

[19] Y. Wu, J. E. Crawford, and J. M. Magallanes, "Performance of LS-DYNA concrete constitutive models," in Proceedings of the 12th International LS-DYNA Users Conference, vol. 1, pp. 114, Dearborn, MI, USA, June 2012.

[20] LSTC, LS-DYNA Keyword User's Manual, Version 971, Livermore Software Technology Corporation, Livermore, CA, USA, 2012.

[21] W. Chen and H. Hao, "Numerical study of a new multi-arch double-layered blast-resistance door panel," International Journal of Impact Engineering, vol. 43, pp. 16-28, 2012.

[22] B. Justusson, J. Pang, M. Molitor, M. Rassaian, and M. Pereira, "The use of depth of penetration testing to develop element erosion parameters in LS-DYNA explicit simulations," in Proceedings of the AIAA Scitech 2019 Forum, p. 2056, San Diego, CA, USA, January 2019.

[23] J. Wu, J. Ning, and T. Ma, "Failure behaviour of concrete subjected to high dynamic loading of new spiral projectile," Defence Science Journal, vol. 68, no. 4, pp. 347-355, 2018.

[24] G. Hou, Basic Course of Rock Mechanics, China Machine Press, Beijing, China, 2011, in Chinese.

[25] X. Y. Wei, Z. Y. Zhao, and J. Gu, "Numerical simulations of rock mass damage induced by underground explosion," International Journal of Rock Mechanics \& Mining Sciences, vol. 46, no. 46, pp. 1206-1213, 2009. 


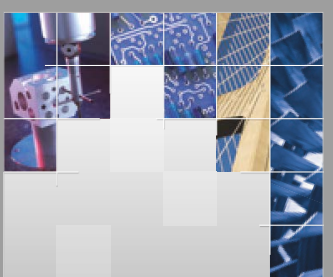

\section{Enfincering}
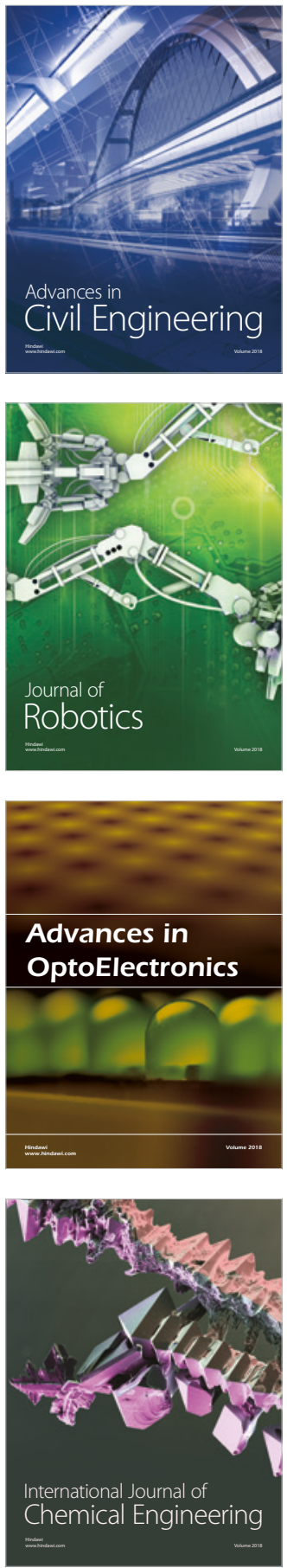

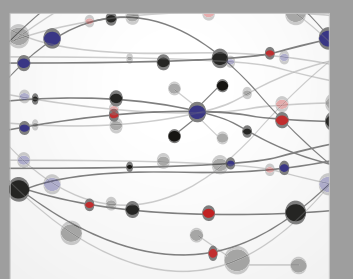

\section{Rotating \\ Machinery}

The Scientific World Journal

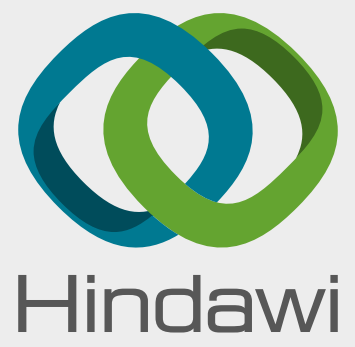

Submit your manuscripts at

www.hindawi.com
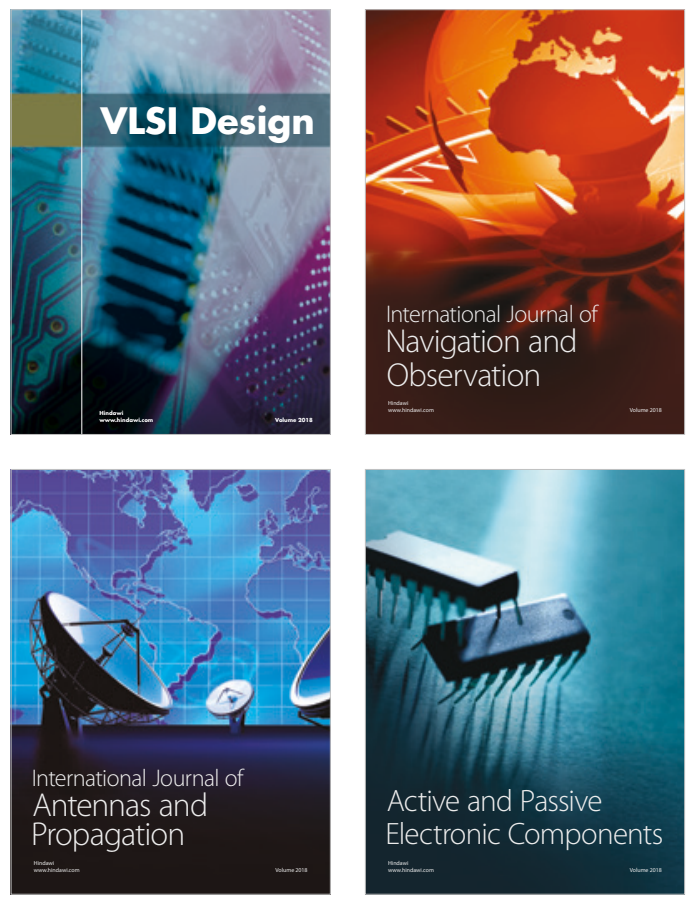
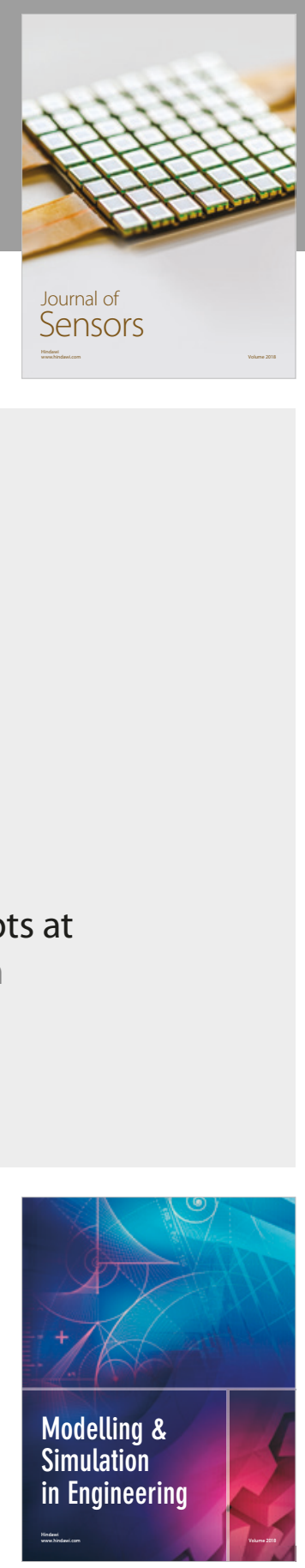

\section{Advances \\ Multimedia}
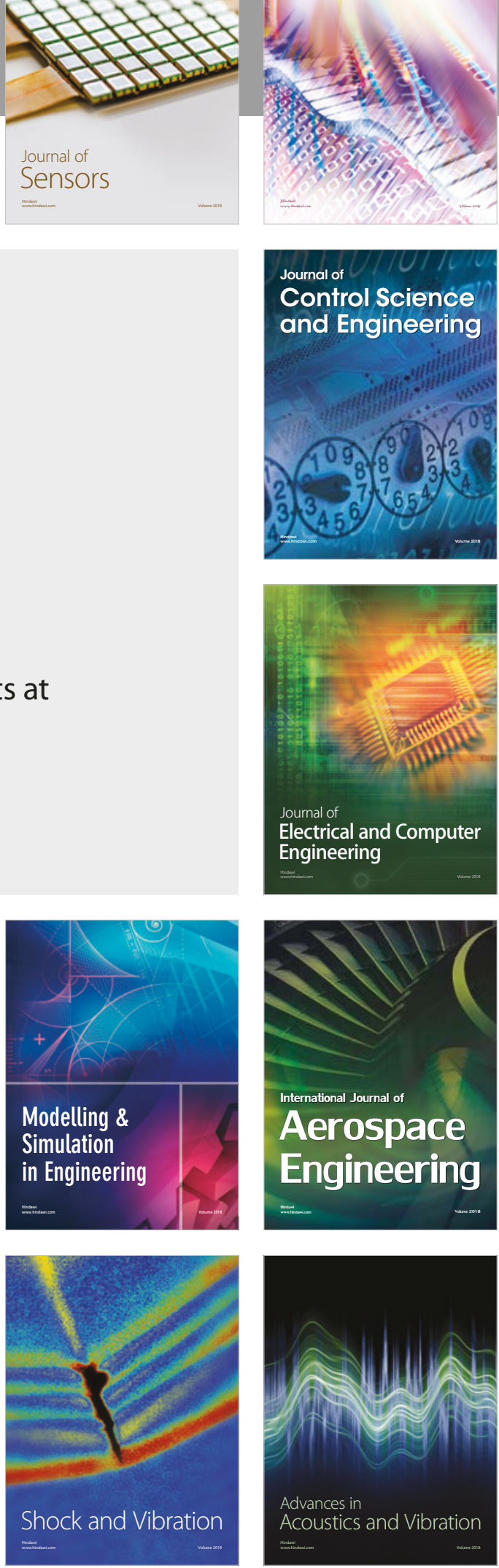